\title{
Effect of increased positive end-expiratory pressure on intracranial pressure and cerebral oxygenation: impact of respiratory mechanics and hypovolemia
}

Han Chen ${ }^{1,2}$, Xiao-Fen Zhou ${ }^{1,2}$, Da-Wei Zhou ${ }^{3}$, Jian-Xin Zhou ${ }^{3}$ and Rong-Guo Yu ${ }^{1,2^{*}}$ (])

\begin{abstract}
Background: To evaluate the impact of positive end-expiratory pressure (PEEP) on intracranial pressure (ICP) in animals with different respiratory mechanics, baseline ICP and volume status.

Methods: A total of 50 male adult Bama miniature pigs were involved in four different protocols $(n=20,12,12$, and 6 , respectively). Under the monitoring of ICP, brain tissue oxygen tension and hemodynamical parameters, PEEP was applied in increments of $5 \mathrm{~cm} \mathrm{H}_{2} \mathrm{O}$ from 5 to $25 \mathrm{~cm} \mathrm{H}_{2} \mathrm{O}$. Measurements were taken in pigs with normal ICP and normovolemia (Series I), or with intracranial hypertension (via inflating intracranial balloon catheter) and normovolemia (Series II), or with intracranial hypertension and hypovolemia (via exsanguination) (Series III). Pigs randomized to the control group received only hydrochloride instillation while the intervention group received additional chest wall strapping. Common carotid arterial blood flow before and after exsanguination at each PEEP level was measured in pigs with intracranial hypertension and chest wall strapping (Series $M$ ).
\end{abstract}

Results: ICP was elevated by increased PEEP in both normal ICP and intracranial hypertension conditions in animals with normal blood volume, while resulted in decreased ICP with PEEP increments in animals with hypovolemia. Increasing PEEP resulted in a decrease in brain tissue oxygen tension in both normovolemic and hypovolemic conditions. The impacts of PEEP on hemodynamical parameters, ICP and brain tissue oxygen tension became more evident with increased chest wall elastance. Compare to normovolemic condition, common carotid arterial blood flow was further lowered when PEEP was raised in the condition of hypovolemia.

Conclusions: The impacts of PEEP on ICP and cerebral oxygenation are determined by both volume status and respiratory mechanics. Potential conditions that may increase chest wall elastance should also be ruled out to avoid the deleterious effects of PEEP.

Keywords: Positive end-expiratory pressure, Intracranial pressure, Cerebral oxygenation, Cerebral blood flow, Respiratory mechanics, Hypovolemia

*Correspondence: garyyrg@126.com; garyyrg@yahoo.com

${ }^{2}$ Department of Critical Care Medicine, Fujian Provincial Hospital, Fuzhou, China

Full list of author information is available at the end of the article

\section{Background}

Mechanical ventilation is frequently needed in the management of patients with acute intracranial hypertension [1]; however, physicians often confront a "lung and brain dilemma," where mechanical ventilation, on the one hand, aims at maintaining adequate 
oxygenation and on the other hand may potentially impair intracranial pressure (ICP) and cerebral blood perfusion. It is still unclear how positive end-expiratory pressure (PEEP) ultimately affects the ICP and cerebral oxygenation. Several studies investigated the impact of elevated PEEP on ICP, which yielded conflicting results. ICP can increase [2-8], not markedly change [9-11], or even decrease [12] after an elevation of PEEP. Several possible determinants for the effect of PEEP on ICP have been proposed, including intracranial compliance, cerebral autoregulation, $\mathrm{CO}_{2}$, intracranial Starling resistor, respiratory system elastance $\left(\mathrm{E}_{\mathrm{RS}}\right)$ and, in the clinical setting, concomitant medical management [13].

A few studies investigated the potential role of $E_{R S}$ $[3,10,11,14]$. In theory, increased PEEP would cause an elevation in intrathoracic pressure and diminished venous return from the brain [15-17]. Cerebral blood volume would increase due to the diminished venous return, and ICP would thus increase [18]. Here, the transmission of PEEP into the thoracic cavity is determined by respiratory mechanics: it has been shown that increased lung elastance $\left(\mathrm{E}_{\mathrm{L}}\right)$ and decreased chest wall elastance $\left(E_{C W}\right)$ can minimize the effect of PEEP on pleural pressure [19]. It is worth noting that both $E_{L}$ and $E_{C W}$ determine $E_{R S}$. In other words, an increased $E_{R S}$ may attribute to either the increase in $E_{L}$ due to pulmonary diseases such as acute respiratory distress syndrome (ARDS), or the rise in $E_{C W}$ due to chest wall impairment such as intra-abdominal hypertension, or both [20]. $\mathrm{E}_{\mathrm{L}}$ and $\mathrm{E}_{\mathrm{CW}}$ were not differentiated in previous studies $[3,10,11,14]$.

Our group explored the impact of PEEP on ICP under different conditions of elevated $E_{R S}$, which attribute to high $E_{L}, E_{C W}$, or both [21]. We found that respiratory mechanics determine the effect of PEEP on ICP: in pigs with normal ICP, an increase of PEEP resulted in increased ICP, where the influence was more evident in the condition of increased $E_{C W}$. However, no inter-group (i.e., increased $\mathrm{E}_{\mathrm{CW}}$ vs. normal $\left.E_{C W}\right)$ difference was observed in pigs with elevated baseline ICP. In addition, because of the severe hypotension induced by high PEEP, ICP decreased (rather than increased) in the intracranial hypertension conditions. Due to the nature of a preliminary study, several important factors were not controlled in that study (e.g., non-random design, $\mathrm{PaCO}_{2}$ not manipulated, unable to measure cerebral blood flow, etc.). In a series of randomized-controlled experimental studies, we reevaluate the impact of PEEP on ICP in animals with different respiratory mechanics, baseline ICP and volume status.

\section{Methods}

Comprehensive methods are available (Additional file 1). Male adult Bama miniature pigs (weight $35-40 \mathrm{~kg}$ ) were used. Animals were purchased from Guangxi University. Humane care was given in compliance with the National Institutes of Health guidelines of experimental animals. By the end of each experiment, the animal was euthanized by overdose pentobarbital (intravenous injection of $120 \mathrm{mg} / \mathrm{kg}$ of pentobarbital). The protocol was approved by the Institutional Review Board and Institutional Animal Care and Use Committee of Fujian Provincial Hospital (Approval \# KY-2016010).

\section{The different impacts of increased PEEP on ICP and cerebral oxygenation in animals with different respiratory mechanics where the ICP is normal-Series I}

Central venous and femoral arterial lines were placed for hemodynamical monitoring and fluid administration. Animals received a tracheotomy and continuous sedation and paralysis. One burr hole was created for ICP and brain tissue oxygen tension $\left(\mathrm{P}_{\mathrm{ti}} \mathrm{O}_{2}\right)$ monitoring. An esophageal catheter was inserted to measure esophageal pressure (i.e., the surrogate of intrathoracic pressure). ARDS (i.e., $E_{L}$ increased) was induced via instillation of $0.1 \mathrm{~mol} / \mathrm{L}$ hydrochloride down the endotracheal tube. $\mathrm{E}_{\mathrm{CW}}$ was raised by chest wall strapping [21]. Animals were ventilated (VT $10 \mathrm{~mL} \mathrm{~kg}^{-1} ; \mathrm{FiO}_{2}$ 1.0; PEEP $5 \mathrm{cmH}_{2} \mathrm{O}$; the rate was initially set to $20 \mathrm{~min}^{-1}$ and adjusted to maintain a $\mathrm{PaCO}_{2}$ between $35-45 \mathrm{mmHg}$ ) and randomized to chest wall strapping or control group (10 per group). PEEP was gradually increased from 5 to $25 \mathrm{cmH}_{2} \mathrm{O}$ in a $5 \mathrm{cmH}_{2} \mathrm{O}$ interval. Hemodynamical parameters, respiratory mechanics, ICP, and $\mathrm{P}_{\mathrm{ti}} \mathrm{O}_{2}$ were measured in each PEEP setting.

\section{The different impacts of increased PEEP on ICP and cerebral oxygenation in animals with different respiratory mechanics where the ICP is elevated-Series II} A second burr hole was created, and a Foley catheter was inserted in this series. ICP was increased by inflating the balloon with saline at a rate of $0.5 \mathrm{~mL} / \mathrm{min}$. The target was a stable ICP level between 25 and $30 \mathrm{cmH}_{2} \mathrm{O}$ for $>30$ min. Animals were also randomized to chest wall strapping or control group (6 per group), and the same data were collected as in Series I.

\section{The impact of PEEP in the condition of blood volume depletion-Series III}

The preparation was as in Series II, except that animals were exsanguinated before randomization. The target of exsanguination was a decrease in cardiac output (CO) by $\geq 20 \%$. Animals were then also randomized ( 6 per 
group), and the same data were collected as in Series I and II.

\section{The different impacts of PEEP on cerebral perfusion between normal and depleted blood volume-Series IV} In this before-after comparison, hemodynamical monitoring and ventilation settings were as in Series I. ARDS was induced, and the chest wall was strapped in all animals (6 animals). ICP monitor and Foley catheters were inserted to produce intracranial hypertension as in Series II. Ultrasonography was used to measure common carotid arterial blood flow: an averaged velocity (V) was measured over an entire respiratory cycle. Vessel diameter (D) was measured at the locations where the flow velocity was measured in M-mode. The blood flow passing the measurement location was calculated as $0.25^{*} \mathrm{~V}^{*} \pi^{*} \mathrm{D}^{2}$. PEEP was stepwise increased and measurements were taken. Animals were then exsanguinated as in Series III. PEEP was increased again, and the blood flow measurements were repeated.

\section{Analysis}

All continuous data were tested for normality of distribution (Shapiro-Wilk) and equal variance, as appropriate. Groups were compared using Mann-Whitney (Rank Sum) tests, and changes over time were examined using Friedman RM-ANOVA on ranks where group distribution was not normal. Where distribution was normal and variance equal, two-way ANOVA or Student's $t$-test was used as appropriate. Significance was established at $p<$ 0.05. Analyses were performed with SPSS Statistics software and GraphPad Prism.

\section{Results}

Details of respiratory mechanics, hemodynamical parameters and blood gas analysis were shown in Additional file 2 . $\mathrm{E}_{\mathrm{CW}}$ was significantly increased by chest wall strapping, while no difference in $\mathrm{E}_{\mathrm{L}}$ was observed between the control and chest wall strapping groups (Additional file 2: Tables S1-S3).

\section{Series I}

ICP increased significantly when PEEP was increased $(p<0.001$ for both groups), and the magnitude was significantly higher in the chest wall strapping group $(p=$ 0.014; Fig. 1A). $\mathrm{P}_{\mathrm{ti}} \mathrm{O}_{2}$ decreased significantly when PEEP was increased ( $p<0.001$ for both groups), but the magnitude was similar between groups ( $p=0.927$; Fig. 1B). $\mathrm{CO}$ and cerebral perfusion pressure (CPP; calculated as mean arterial pressure minus ICP) decreased with PEEP increment ( $p<0.001$ for both groups), while no difference was observed between groups $(p=0.907$ and 0.645 , respectively; Fig. $1 \mathrm{C}, \mathrm{D})$. CO, blood pressure and $\mathrm{CPP}$ were preserved in a "physiological" range in each PEEP level.

\section{Series II}

Similar to Series $I$, the increment of PEEP resulted in a greater elevation of ICP in the chest wall strapping group $(p=0.022$; Fig. $2 \mathrm{~A}) . \mathrm{P}_{\mathrm{ti}} \mathrm{O}_{2}$ decreased significantly when PEEP was increased ( $p<0.001$ for both groups), but no difference was observed between the two groups ( $p=$ 0.333; Fig. 2B). CO and CPP decreased when PEEP was increased ( $p<0.001$ for both groups), while no intergroup difference was observed $(p=0.649$ and 0.367 , respectively; Fig. $2 \mathrm{C}, \mathrm{D})$. $\mathrm{CO}$ and blood pressure can be maintained in a "physiological" range, while CPP was lower than $60 \mathrm{mmHg}$ when PEEP was $\geq 20 \mathrm{cmH}_{2} \mathrm{O}$ (Fig. 2D).

\section{Series III}

In the contrast of Series $I$ and $I I$, the increment of PEEP caused a decrease of ICP when animals were exsanguinated ( $p<0.001$ for both groups). A significantly greater decrease was observed in the chest wall strapping group $\left(p=0.018\right.$; Fig. 3A). $\mathrm{P}_{\mathrm{ti}} \mathrm{O}_{2}$ decreased when PEEP was increased ( $p<0.001$ for both groups), and the magnitude was greater in the chest wall strapping group $(p=$ 0.020; Fig. 3B). CO and CPP also decreased when PEEP was increased ( $p<0.001$ for both groups). There was a significantly greater drop in $\mathrm{CO}$ in the chest wall strapping group ( $p=0.020$; Fig. $3 C)$. No significant difference was observed in CPP ( $p=0.205$; Fig. 3D). CPP was lower than $60 \mathrm{mmHg}$ when PEEP was $\geq 15 \mathrm{cmH}_{2} \mathrm{O}$.

\section{Series IV}

Compare to baseline, exsanguinated resulted in a greater drop of CO to the same increment of PEEP $(p<0.001$; Fig. 4B). A significant greater drop of common carotid arterial blood flow was observed following the decrease of $\mathrm{CO}(p<0.001$; Fig. $4 \mathrm{~A})$.

\section{Discussion}

The main findings of our study were: (1) ICP was elevated by increased PEEP in both normal ICP and intracranial hypertension conditions in animals with normal blood volume (Series $I$ and II); (2) Increasing PEEP resulted in decreased ICP if the animals were volume-depleted (Series III); (3) Increasing PEEP resulted in decrease in $\mathrm{P}_{\mathrm{ti}} \mathrm{O}_{2}$ in either normovolemic or hypovolemic conditions (Series I-III); (4) The impact of PEEP on hemodynamical parameters, ICP and $\mathrm{P}_{\mathrm{ti}} \mathrm{O}_{2}$ became more evident when $\mathrm{E}_{\mathrm{CW}}$ was increased (Series I-III); (5) Compare to normovolemic condition, common carotid arterial blood flow was further lowered when PEEP was raised in the 


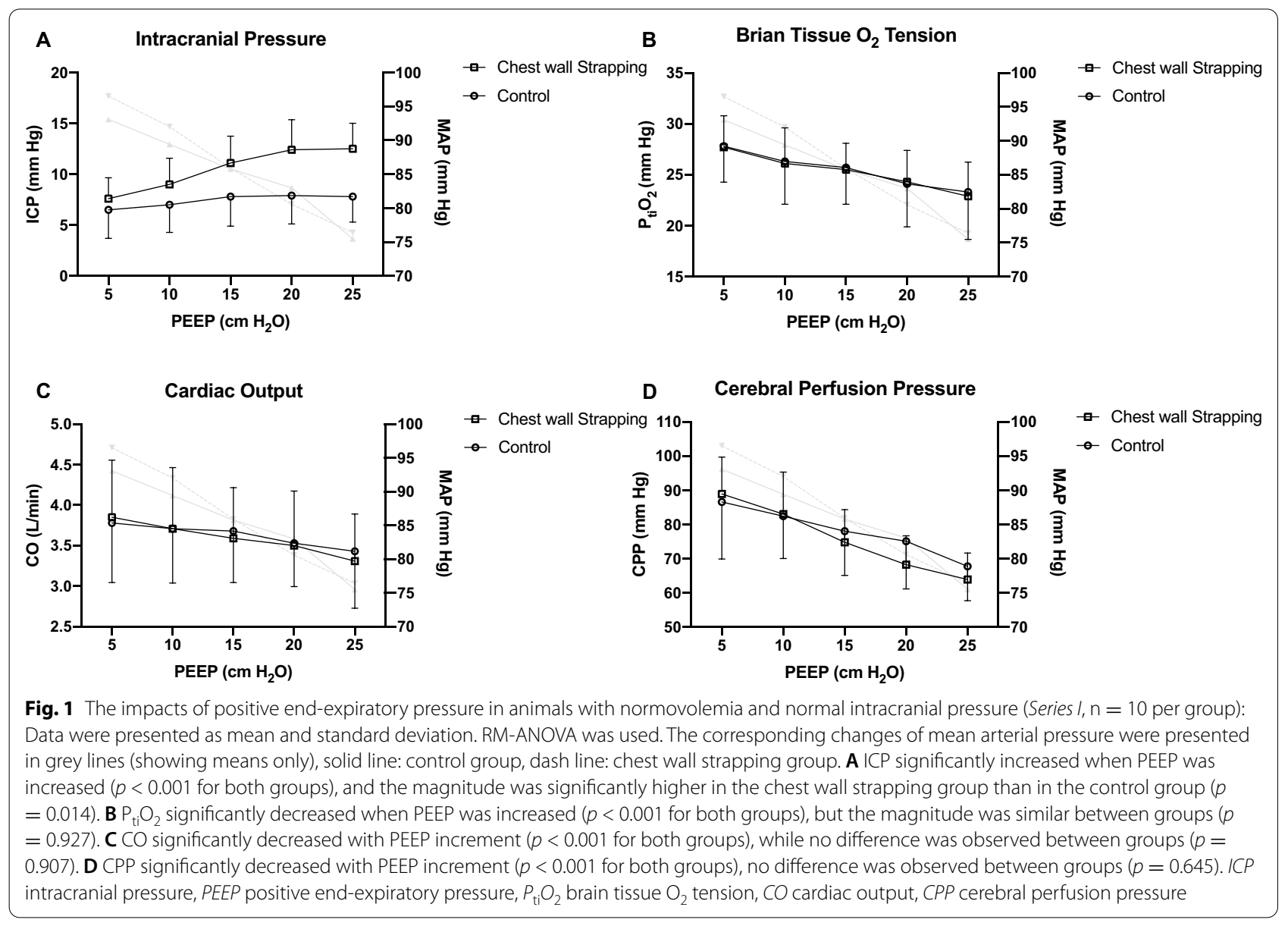

condition of hypovolemia, which was probably the cause of lowered ICP and $\mathrm{P}_{\mathrm{ti}} \mathrm{O}_{2}$ (Series IV).

As shown by Chapin et al., the transmission of airway pressure to pleural pressure depends on the relative compliance of the lung and the chest wall. The transmission is less "efficient" with increased $\mathrm{E}_{\mathrm{L}}$ and decreased $\mathrm{E}_{\mathrm{CW}}$ [19]. This means that the applied PEEP in ARDS (a common condition of increased $\mathrm{E}_{\mathrm{L}}$ ) is less likely to be transmitted into the pleural space, and thus has less impact on central venous pressure and cerebral venous return. In other words, although a high PEEP is usually applied in the treatment of ARDS, the pulmonary disease per se might be a "protective" factor against the deleterious effects of PEEP to the brain. However, $E_{L}$ is not routinely measured in clinical settings; instead, $E_{R S}$ was often considered synonymous of $E_{L}$. One should keep in mind that $E_{R S}$ and $E_{L}$ are not interchangeable because $E_{C W}$ is also a key determinant of $E_{\mathrm{RS}}$. Our data from Series I to III clearly demonstrated that an increased $\mathrm{E}_{\mathrm{CW}}$ resulted in a more considerable influence of PEEP on ICP. Our finding suggests that the possible underlining conditions which can increase $\mathrm{E}_{\mathrm{CW}}$ (e.g., intra-abdominal hypertension due to gastrointestinal retention, or the need for rib fixation due to traumatic rib fractures, which are not rare in clinical settings) must be ruled out before a high PEEP is applied in brain-injured patients.

In contrast to the normovolemic conditions (Series $I$ and $I I$ ), raising PEEP resulted in decreased ICP if the animals were volume-depleted (Series III). This can be explained by the influence of PEEP on $\mathrm{CO}$ and thus cerebral perfusion. As proposed in a conceptual framework that the two important determinants of the impact of elevating PEEP on ICP are the intracranial compliance and the "net" change of cerebral blood volume (CBV); the latter is determined by the balance between the arterial inflow (regulated by $\mathrm{CO}$, cerebral autoregulation, $\mathrm{PaCO}_{2}$, etc.) and venous outflow (regulated by PEEP, Starling resistor, etc.). Increased PEEP and subsequent increased pleural pressure impede the global venous return to the heart, lead to a decrease in $\mathrm{CO}$ and cerebral perfusion [22, 23]. The effect is more profound in the volume-depleted condition [24], as was observed in Series III. In this case, the influence of decreased CO (which reduces arterial inflow and decreases CBV) exceeded 

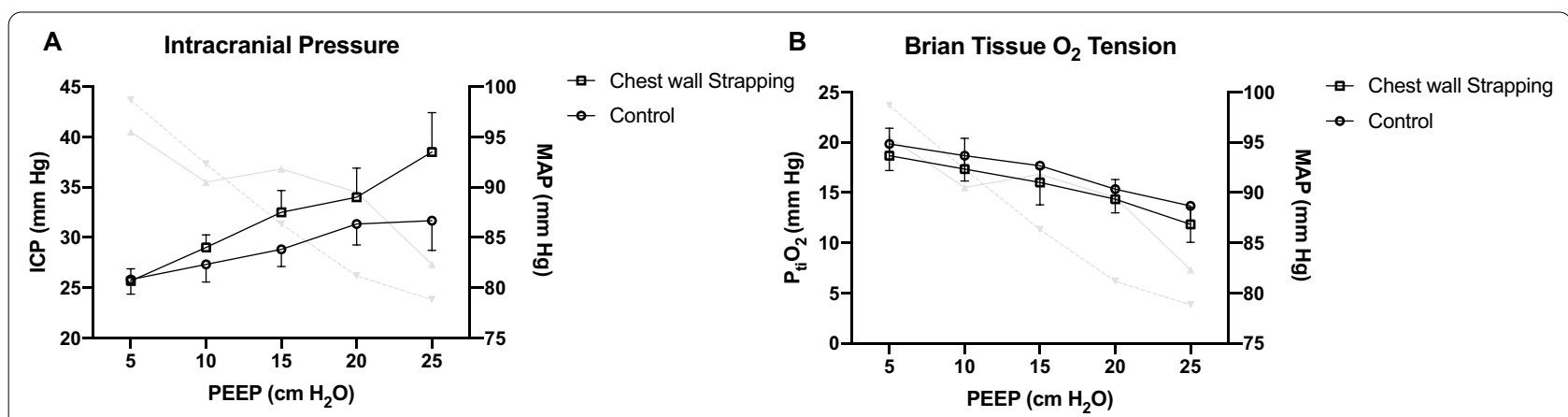

C

Cardiac Output

D

Cerebral Perfusion Pressure
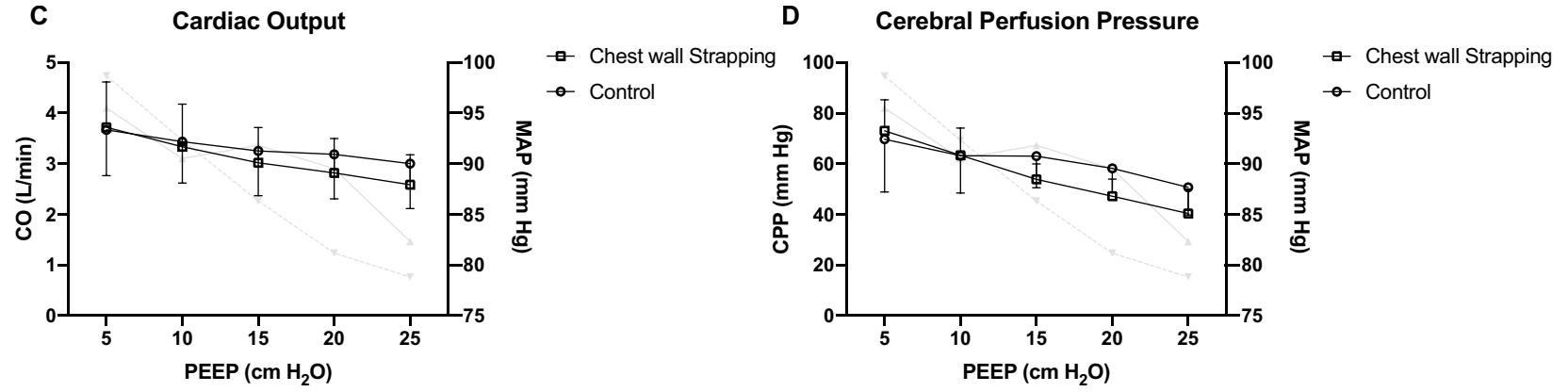

Fig. 2 The impacts of positive end-expiratory pressure in animals with normovolemia and intracranial hypertension (Series II, $\mathrm{n}=6$ per group). Data were presented as mean and standard deviation. RM-ANOVA was used. The corresponding changes of mean arterial pressure were presented in grey lines (showing means only), solid line: control group, dash line: chest wall strapping group. A ICP significantly increased when PEEP was increased ( $p<0.001$ for both groups), and the magnitude was significantly higher in the chest wall strapping group than in the control group ( $p$ $=0.022)$. $\mathbf{B} P_{\mathrm{ti}} \mathrm{O}_{2}$ significantly decreased when PEEP was increased ( $p<0.001$ for both groups), but the magnitude was similar between groups $(p$ $=0.333)$. C CO significantly decreased with PEEP increment ( $p<0.001$ for both groups), while no difference was observed between groups $(p=$ 0.649). D CPP significantly decreased with PEEP increment ( $p<0.001$ for both groups), no difference was observed between groups ( $p=0.367)$. ICP intracranial pressure, $P E E P$ positive end-expiratory pressure, $P_{\mathrm{ti}} \mathrm{O}_{2}$ brain tissue $\mathrm{O}_{2}$ tension, $C O$ cardiac output, $C P P$ cerebral perfusion pressure

the influence of decreased venous return (which reduces venous outflow and increases $C B V$ ), which resulted in a negative "net" change of CBV and eventually a decreased ICP.

Mean arterial pressure (MAP) and CPP were also lower when high PEEP levels were applied. In animals with intact cerebral autoregulation, vessels in the brain can maintain a constant cerebral blood flow via regulating the vascular tone throughout a wide range of MAP or CPP $[25,26]$. In the present study, CPP dropped beyond the lower limit of autoregulation when high PEEP levels were selected in animals received exsanguination (Series III). Therefore, the most possible cause of lowered ICP and $\mathrm{P}_{\mathrm{ti}} \mathrm{O}_{2}$ was decreased cerebral perfusion. More data was obtained to support the concept in Series IV. We measured the blood flow in the common carotid artery and a significantly greater decrease of blood flow was observed after exsanguination when the same PEEP was applied. Take all data together, we can conclude that PEEP can affect ICP predominantly via its hemodynamical effects, which always functions on both the arterial (perfusion) and venous (returning) sides simultaneously. And here, increased $\mathrm{E}_{\mathrm{CW}}$ amplifies the effects of PEEP.
$\mathrm{P}_{\mathrm{ti}} \mathrm{O}_{2}$ was also measured in the present study, and we found that increasing PEEP resulted in decreased $\mathrm{P}_{\mathrm{ti}} \mathrm{O}_{2}$ in either normovolemic or hypovolemic conditions. The impact of PEEP on cerebral oxygenation was not well understood yet. Results from previous studies are variable [3, 9, 27]. In traumatic brain injury patients with ARDS, a progressively raising of PEEP (from 5 to 15 $\mathrm{cmH}_{2} \mathrm{O}$ ) improved $\mathrm{P}_{\mathrm{ti}} \mathrm{O}_{2}$ [9]. In an experimental study, a raising-PEEP strategy was carried out in healthy pigs where no impact on $\mathrm{P}_{\mathrm{ti}} \mathrm{O}_{2}$ was observed. The conflicts of our data to previous studies can be explained as follows: assuming a relatively constant $\mathrm{O}_{2}$ consumption, the change of $\mathrm{P}_{\mathrm{ti}} \mathrm{O}_{2}$ should be the consequence of changed $\mathrm{O}_{2}$ delivery. Thus, the two key determinants of $\mathrm{O}_{2}$ delivery to the brain were $\mathrm{CO}$ and arterial $\mathrm{O}_{2}$ saturation. Unlike Nemer's study where increasing PEEP resulted in a considerable improvement in $\mathrm{P} / \mathrm{F}$ ratio (from 108.5 to $203.6 \mathrm{mmHg}$ ), the improvement in $\mathrm{P} / \mathrm{F}$ ratio was less obvious (although statistically significant, Additional file 1: Fig. S1-S3) in the present study; moreover, $\mathrm{O}_{2}$ saturation was $100 \%$ already and thus further increase was not possible since the $\mathrm{FiO}_{2}$ was 1.0 in the first place. On the other hand, $\mathrm{CO}$ was decreased 

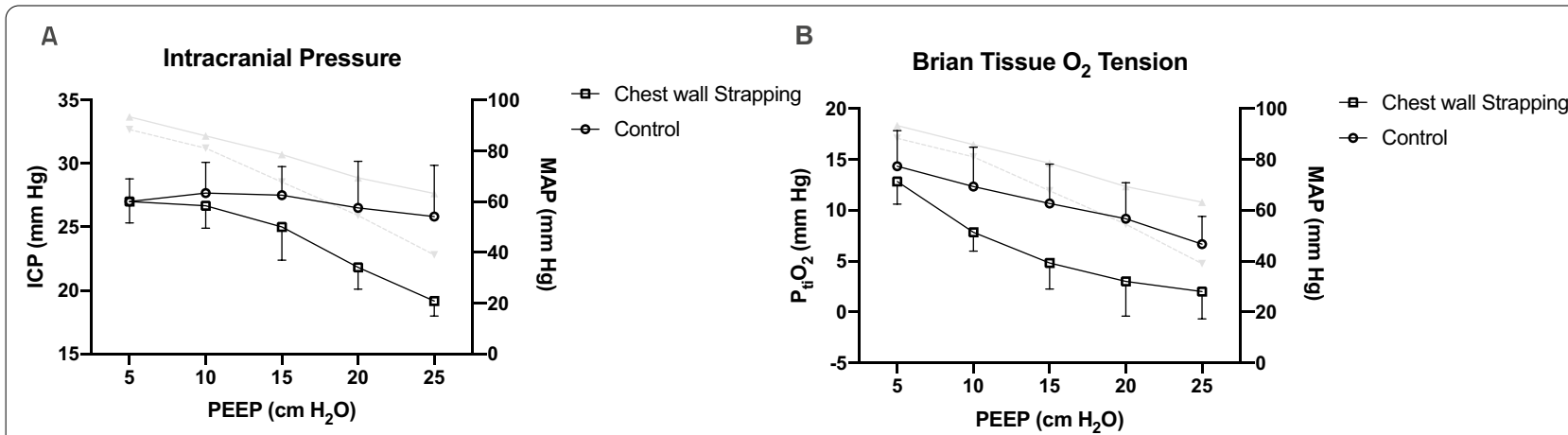

C
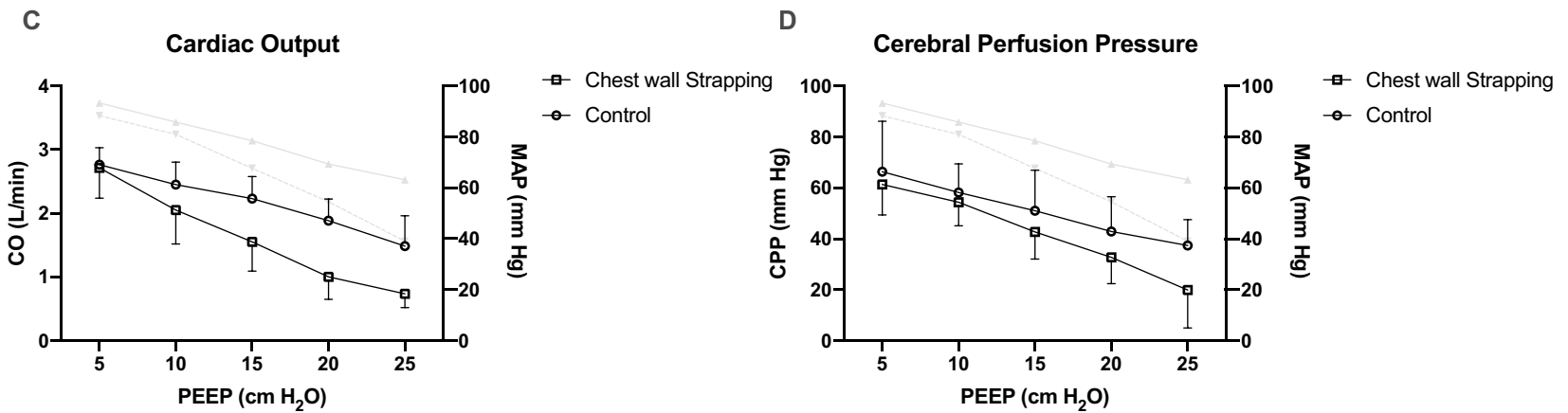

Fig. 3 The impacts of positive end-expiratory pressure in animals with hypovolemia and intracranial hypertension (Series III, $\mathrm{n}=6$ per group). Data were presented as mean and standard deviation. RM-ANOVA was used. The corresponding changes of mean arterial pressure were presented in grey lines (showing means only), solid line: control group, dash line: chest wall strapping group. A ICP significantly decreased when PEEP was increased ( $p<0.001$ for both groups), and the magnitude was significantly greater in the chest wall strapping group than in the control group ( $p=$ 0.018). $\mathbf{B} P_{\mathrm{ti}} \mathrm{O}_{2}$ decreased when PEEP was increased ( $p<0.001$ for both groups), and the magnitude was greater in the chest wall strapping group than in the control group $(p=0.020)$. C CO significantly decreased with PEEP increment ( $p<0.001$ for both groups), there was a significantly greater decrease in $\mathrm{CO}$ in the chest wall strapping group than in the control group $(p=0.020)$. D CPP significantly decreased with PEEP increment $(p<$ 0.001 for both groups), no difference was observed between groups $(P=0.205)$. ICP intracranial pressure, $P E E P$ positive end-expiratory pressure, $P_{\mathrm{ti}} \mathrm{O}_{2}$ brain tissue $\mathrm{O}_{2}$ tension, $\mathrm{CO}$ cardiac output, $C P P$ cerebral perfusion pressure
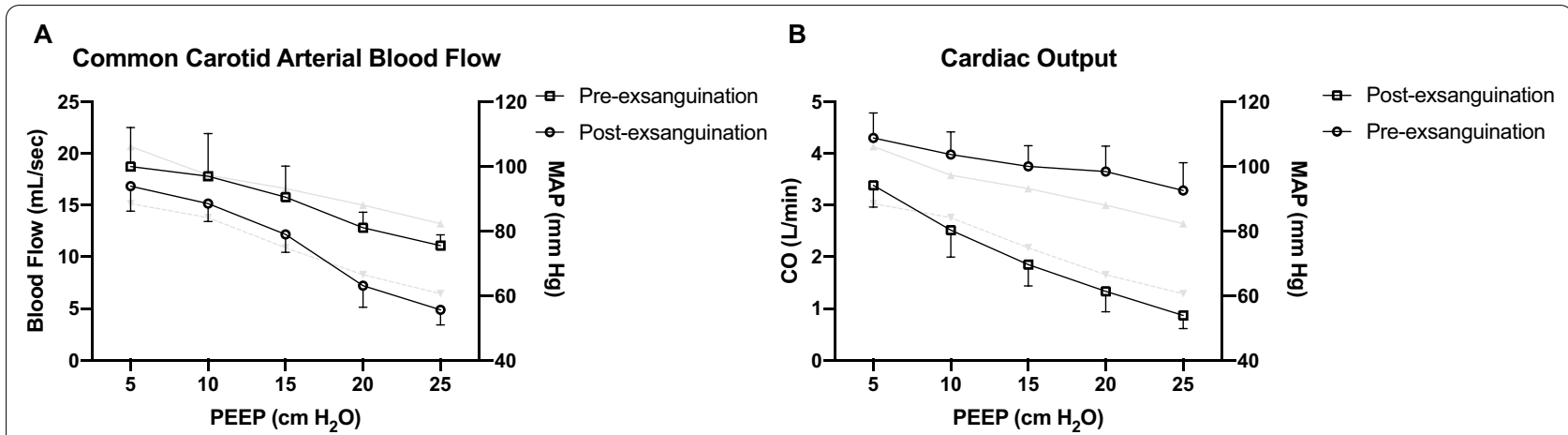

Fig. 4 The impacts of positive end-expiratory pressure on common carotid arterial blood flow (Series $I, n=6$ ). Data were presented as mean and standard deviation. RM-ANOVA was used. The corresponding changes of mean arterial pressure were presented in grey lines (showing means only), solid line: pre-exsanguination, dash line: post-exsanguination. A Common carotid arterial blood flow decreased significantly when PEEP was increased ( $p<0.001$ for both conditions), and the magnitude was significantly greater in the post-exsanguination (i.e., hypovolemic) condition than in the pre-exsanguination (i.e., normovolemic) condition $(p<0.001)$. B CO significantly decreased with PEEP increment ( $p<0.001$ for both conditions), there was a significantly greater decrease in $\mathrm{CO}$ in the post-exsanguination condition than in the pre-exsanguination condition $(p<$ 0.001). PEEP positive end-expiratory pressure, CO cardiac output 
following PEEP increments. Therefore, $\mathrm{P}_{\mathrm{ti}} \mathrm{O}_{2}$ decreased due to a decreased CO.

It is also interesting to know the influence of increased PEEP on ICP and other parameters in animals with normal ICP (like in Series I) but with depleted blood volume (like in Series III). In fact, we did perform some pilot experiments to exam this. Briefly, a crossover rather than a randomized-control experiment was completed in four pilot animals with normal ICP and depleted blood volume (two from chest wall strapping to control condition and the other two in the inverse order). ICP decreased with the increment of PEEP in all animals, but the magnitude was small (from 8.5 to $6.8 \mathrm{mmHg}$ in the control condition and from 7.1 to $4.8 \mathrm{mmHg}$ in the chest wall strapping condition with PEEP increment, Additional file 2: Fig. S4). The reason we did not further perform a randomized-control study with a larger sample size were: first, the trend of ICP change in the pilot study was the same as we observed in Series III, and the underlying pathophysiology rationale could be the same; second, considering the small difference in the change of ICP between the two conditions, large sample size is required to obtain a statistical significance, which may deviate from the ethical requirements of animal experiments. Therefore, we finished only one randomized-control study (Series III) to exam the impact of hypovolemia and speculated that the conclusion might also be true in animals with normal ICP, although without additional experiments.

Our study has some limitations: (1) The data were obtained with experiments of short duration; therefore, the long term effects of PEEP were still unclear; (2) Blood flow was measured at the common carotid artery rather than the internal carotid artery (which perfuse the brain). In the present study, we used a Vevo 3100 ultrasonic system with an ultra-high-frequency probe designed for small animal research. The ultra-high-frequency probe provided high resolution while the maximal scan depth was limited. The internal carotid artery was too deep to display by using the current device, so we chose common carotid artery instead; (3) Although a decreased cerebral venous return was proposed as the main reason for increased ICP, the outflow was not measured in this study. We measured arterial blood flow via Doppler ultrasound; however, using the same methodology to assess cerebral venous return was suggested to be inaccurate [28]; (4) Indeed, ICP has four components: besides arterial blood inflow and venous blood outflow discussed above, cerebrospinal fluid (CSF) circulation and volumetric changes of brain tissue or contusion volume also play an important role. We did not directly measure the change of CSF circulation and brain tissue volume in the present study. Considering the short experimental period, brain tissue volume can be assumed unchanged, while the change of CSF circulation was not investigated in a quantitative way but a qualitative way instead (Series $I$ vs. Series II). In other words, the four components of ICP were not investigated in isolation and the quantitative way in the present study and thus may limit our interpretation of the effects of a specific factor. Moreover, several other factors that may have an impact on these four components, such as pulse amplitude, respiratory wave amplitude and pressure reactive index (as a surrogate of cerebral autoregulation) were not considered in the present study. (5) The present study investigates only two different volume statuses (normovolemia vs. massive blood loss) while intermediate states, for example, mild hypovolemia due to diuretics or hyperosmolar agents, or small amount of blood loss, are more likely to occur in the clinical setting. Further studies are necessary to confirm the effects of PEEP in these situations.

\section{Conclusions}

Both volume status and respiratory mechanics determine the impacts of PEEP on ICP and cerebral oxygenation. PEEP increases ICP in stable hemodynamic conditions while decreases ICP in hypovolemia. The effects are more profound when $\mathrm{E}_{\mathrm{CW}}$ is high. In brain-injured patients, PEEP should be applied under the monitoring of MAP, ICP, and CPP; meanwhile, potential conditions that may increase $\mathrm{E}_{\mathrm{CW}}$ should be ruled out to avoid the deleterious effects of PEEP.

\section{Abbreviations \\ ARDS: Acute respiratory distress syndrome; CO: Cardiac output; CPP: Cerebral perfusion pressure; $E_{C W}$ : Chest wall elastance; $E_{L}$ : Lung elastance; $E_{R S}$ : Respira- tory system elastance; ICP: Intracranial pressure; MAP: Mean arterial pressure; PEEP: Positive end-expiratory pressure; $\mathrm{P}_{\mathrm{ti}} \mathrm{O}_{2}$ : Brain tissue oxygen tension; $\mathrm{VT}$ : Tidal volume.}

\section{Supplementary Information}

The online version contains supplementary material available at https://doi. org/10.1186/s12868-021-00674-9.

Additional file 1. Comprehensive experimental methods.

Additional file 2. Details of respiratory mechanics, hemodynamical parameters and blood gas analysis.

\section{Acknowledgements}

None

Authors' contributions

Conception and design: HC, XFZ, JXZ, RGY; Experiment and Data collection: HC, XFZ, DWZ; Drafting the manuscript for important intellectual content: $H C$, XFZ, JXZ, RGY. All authors read and approved the final manuscript.

\section{Funding}

$\mathrm{HC}$ is supported by the National Natural Science Foundation of China (Grant No. 81701942) and the High-level Hospital Foster Grants from Fujian Provincial Hospital (Grant Number: 2020HSJJ02). Xiao-Fen Zhou is supported by General 
Program of Natural Science Foundation of Fujian Provincial (Grant Number: 2019J01499). The funding bodies have no role in the design of the study and collection, analysis, and interpretation of data and in writing the manuscript.

\section{Availability of data and materials}

The datasets used and/or analyzed during the present study are available from the corresponding author on reasonable request.

\section{Declarations}

\section{Ethics approval and consent to participate}

The protocol was approved by the Institutional Review Board and Institutional Animal Care and Use Committee of Fujian Provincial Hospital (Approval \# KY-2016010). All experiments were performed according to the guidelines of the Institutional Biosafety Committee and Animal Care Committee of Fujian Provincial Hospital.

\section{Consent for publication}

Not applicable.

\section{Competing interests}

The authors declare that they have no competing interests

\section{Author details}

${ }^{1}$ Fujian Shengli Clinical Medical College, Fujian Medical University, Fuzhou, China. ${ }^{2}$ Department of Critical Care Medicine, Fujian Provincial Hospital, Fuzhou, China. ${ }^{3}$ Department of Critical Care Medicine, Beijing Tiantan Hospital, Capital Medical University, Beijing, China.

Received: 10 July 2020 Accepted: 2 November 2021

Published online: 25 November 2021

\section{References}

1. Carney N, Totten AM, O'Reilly C, Ullman JS, Hawryluk GW, Bell MJ, et al. Guidelines for the Management of Severe Traumatic Brain Injury, Fourth Edition. Neurosurgery. 2017;80:6-15.

2. Lima WA, Campelo AR, Gomes RL, Brandao DC. The impact of positive end-expiratory pressure on cerebral perfusion pressure in adult patients with hemorrhagic stroke. Rev Bras Ter Intensiva. 2011;23:291-6.

3. Mascia L, Grasso S, Fiore T, Bruno F, Berardino M, Ducati A. Cerebropulmonary interactions during the application of low levels of positive end-expiratory pressure. Intensive Care Med. 2005;31:373-9.

4. Ludwig HC, Klingler M, Timmermann A, Weyland W, Mursch K, Reparon $C$, et al. The influence of airway pressure changes on intracranial pressure (ICP) and the blood flow velocity in the middle cerebral artery (VMCA). Anasthesiol Intensivmed Notfallmed Schmerzther. 2000;35:141-5.

5. McGuire G, Crossley D, Richards J, Wong D. Effects of varying levels of positive end-expiratory pressure on intracranial pressure and cerebral perfusion pressure. Crit Care Med. 1997;25:1059-62.

6. Cooper KR, Boswell PA, Choi SC. Safe use of PEEP in patients with severe head injury. J Neurosurg. 1985;63:552-5.

7. Burchiel KJ, Steege TD, Wyler AR. Intracranial pressure changes in braininjured patients requiring positive end-expiratory pressure ventilation. Neurosurgery. 1981;8:443-9.

8. Shapiro HM, Marshall LF. Intracranial pressure responses to PEEP in headinjured patients. J Trauma. 1978;18:254-6.

9. Nemer SN, Caldeira JB, Santos RG, Guimaraes BL, Garcia JM, Prado D, et al. Effects of positive end-expiratory pressure on brain tissue oxygen pressure of severe traumatic brain injury patients with acute respiratory distress syndrome: A pilot study. J Crit Care. 2015;30:1263-6.
10. Caricato A, Conti G, Della Corte F, Mancino A, Santilli F, Sandroni C, et al. Effects of PEEP on the intracranial system of patients with head injury and subarachnoid hemorrhage: the role of respiratory system compliance. J Trauma. 2005;58:571-6.

11. Frost EA. Effects of positive end-expiratory pressure on intracranial pressure and compliance in brain-injured patients. J Neurosurg. 1977;47:195-200.

12. Huynh T, Messer M, Sing RF, Miles W, Jacobs DG, Thomason MH. Positive end-expiratory pressure alters intracranial and cerebral perfusion pressure in severe traumatic brain injury. J Trauma. 2002;53:488-92 (discussion 92-3).

13. Chen H, Menon DK, Kavanagh BP. Impact of altered airway pressure on intracranial pressure, perfusion, and oxygenation: a narrative review. Crit Care Med. 2019;47:254-63.

14. Aidinis SJ, Lafferty J, Shapiro HM. Intracranial responses to PEEP. Anesthesiology. 1976;45:275-86.

15. Kurishima C, Tsuda M, Shiima Y, Kasai M, Abe S, Ohata J, et al. Coupling of central venous pressure and intracranial pressure in a 6-year-old patient with fontan circulation and intracranial hemorrhage. Ann Thorac Surg. 2011;91:1611-3.

16. Chang WT, Nyquist PA. Strategies for the use of mechanical ventilation in the neurologic intensive care unit. Neurosurg Clin N Am. 2013;24:407-16.

17. Asehnoune K, Roquilly A, Cinotti R. Respiratory Management in Patients with Severe Brain Injury. Crit Care. 2018;22:76.

18. Wilson MH. Monro-Kellie 2.0: The dynamic vascular and venous pathophysiological components of intracranial pressure. J Cereb Blood Flow Metab. 2016;36:1338-50.

19. Chapin JC, Downs JB, Douglas ME, Murphy EJ, Ruiz BC. Lung expansion, airway pressure transmission, and positive end-expiratory pressure. Arch Surg. 1979;114:1193-7.

20. Gattinoni L, Chiumello D, Carlesso E, Valenza F. Bench-to-bedside review: chest wall elastance in acute lung injury/acute respiratory distress syndrome patients. Crit Care. 2004;8:350-5.

21. Chen H, Zhou J, Lin YQ, Zhou JX, Yu RG. Intracranial pressure responsiveness to positive end-expiratory pressure in different respiratory mechanics: a preliminary experimental study in pigs. BMC Neurol. 2018;18:183.

22. Funk DJ, Jacobsohn E, Kumar A. Role of the venous return in critical illness and shock: part II-shock and mechanical ventilation. Crit Care Med. 2013;41:573-9.

23. Funk DJ, Jacobsohn E, Kumar A. The role of venous return in critical illness and shock-part I: physiology. Crit Care Med. 2013;41:255-62.

24. Magder S. Volume and its relationship to cardiac output and venous return. Crit Care. 2016;20:271.

25. McBryde FD, Malpas SC, Paton JF. Intracranial mechanisms for preserving brain blood flow in health and disease. Acta Physiol (Oxf). 2017;219:274-87.

26. Kinoshita K. Traumatic brain injury: pathophysiology for neurocritical care J Intensive Care. 2016;4:29.

27. Muench E, Bauhuf C, Roth H, Horn P, Phillips M, Marquetant N, et al. Effects of positive end-expiratory pressure on regional cerebral blood flow, intracranial pressure, and brain tissue oxygenation. Crit Care Med. 2005;33:2367-72.

28. Zamboni P. Why Current Doppler Ultrasound Methodology Is Inaccurate in Assessing Cerebral Venous Return: The Alternative of the Ultrasonic Jugular Venous Pulse. Behav Neurol. 2016;2016:7082856.

\section{Publisher's Note}

Springer Nature remains neutral with regard to jurisdictional claims in published maps and institutional affiliations. 